\title{
Negotiating experience in patient involvement: Challenges of practicing storytelling in health care conversations
}

Morten Deleuran Terkildsen \& Inge Wittrup

Public Health and Quality Improvement, Central Denmark Region Interacting Minds Centre (IMC), Aarhus University Institute for Public Health, Aarhus University Morten.terkildsen@stab.rm.dk,inge.wittrup@stab.rm.dk

Terkildsen, M. D. \& Wittrup, I. (2015). Negotiating Experience in Patient Involvement - Challenges of Practicing Storytelling in Health Care Conversations. Tidsskrift for Forskning i Sygdom og Samfund, nr. 22, 45-65.

This paper investigates the challenges of integrating patient experiences in patient involving health care interventions. Experience occupying a central importance is often perceived to be something inherent to the patient to be communicated to the health professional during conversations. Yet drawing on empirical material from an 'Intercultural Health Conversation' and by departing in anthropological debates seeing experience as something socially expressed and negotiated this article demonstrates how boundaries and constraints emerge when experiences become socially expressed through the practice of storytelling in conversations in health care. 


\section{Introduction}

Recent focus on the notion of patient involvement has ushered an interest to see patients as important and active co-producers in improving their own health situation (Coulter 2011). Especially as studies have shown that patient involvement has strong potentials for improving health care services for those regarded having fewer resources (Coulter 2012).

The notion of patient involvement, although seen as rising in popularity, still carries a shroud of mist with regards to its actual definition. A 2012 report (European Commission 2012) on patient involvement by the European Commission concluded that the notion of patient involvement, although identified as being central to the health care system of the future, still comes across as being rather vaguely defined both by those planning health care interventions as well as those working with it in practice - a conclusion backed by systematic reviews (ex. Mockford et al. 2012).

Under the umbrella of patient involvement, a whole new range of concepts have been introduced. Concepts such as patient-centeredness, which can be seen as a paradigmatic shift (Riskjær 2012; 2014) establishing a partnership between clinicians, patients, and relatives (Institute of Medicine 2001); patient involvement, which is used synonymously with patient-centeredness (Riskjær 2012) demarcating a closer attention to detail (Thomson 2007; Sheridan 2004); empowerment, which focuses on acknowledgement of patients' experiences, priorities, and fear (Aujoulat et al. 2007); and shared decision making, which stresses the presence of at least two persons - the health professional and the patient - who through both conversations and actions share information and take steps to reach consensus (Lomborg 2013). Here, we stick to the notion of patient involvement in its widest sense.

The proliferation of these concepts testifies to a paradigmatic shift at the centre of which stands a shared wish to solicit the patient's commitment and resources and to tap into the patient's experiences to improve responsiveness and secure active patients by engaging their resources (Coulter 2011). Here patients' experiences become of central importance seemingly adding something to the success of health care interventions.

The patients' experiences emerge as a dual construction serving both a sensemaking purpose to the patient him- or herself and an interaction purpose in the sense that the patient shares his or her experience with the health professional during care interventions. Experience is thus seen as something belonging to the 
patient to be directly understood by the health professionals and integrated in the health intervention (Lomborg 2013; Zimmermann et al. 2007).

The creation of the necessary space and capacity for this seemingly straight forward communication in health care interventions is perceived to be one of the main challenges of involving patients' experiences in practice. Here conversations have taken centre stage.

Conversations, the act of storytelling with patients forging a diagnostic story, have long been recognized as a fundamental and integrated part of medicine and the medical profession. Yet, in the wake of the new paradigm of patient involvement, conversations are no longer to be perceived only as a frame for medical diagnostics, but also as a scene for understanding the patient's situation and experiences leading to better health care interventions (Lomborg 2013). This is our point of departure.

Empirically we draw on data collected during a patient involvement pilot-project in healthcare departments in five municipalities in Central Denmark Region, the purpose of which was to develop an Intercultural Health Conversation, allowing people from ethnic minorities suffering from complex health problems to unfold their illness experiences and together with the health professionals turning these experiences into patient involving interventions.

Departing in an anthropological discussion of the notion of experience, in these discussions seen as something expressed and negotiated through social practices, this article uses a narrative analytical frame to explore the challenges of providing patient involvement, integrating patient experiences in healthcare interventions by means of conversation.

\section{Patient involvement in practice}

In 2010, the pilot-project 'Intercultural Health Promotion and Rehabilitation' was designed as a patient involvement programme, aiming at reducing health inequalities among patients from ethnic minorities by initiating interventions based on patient experiences of health problems. The project was initiated by Central Denmark Region, funded by The Fund for Better Working Environment and Labour Retention and The Health Foundation and implemented in the municipalities of Randers, Holstebro, Herning, Horsens and Aarhus.

Studies have shown that ethnic minorities were found to be vulnerable when it comes to the effects of a lower health status (Bhopal 2012); that ethnic minori- 
ties were suffering from long-term illness, several co-existing diseases, a higher proportion of low mental health (Singhammer 2008); a higher risk of developing diabetes mellitus (Kristensen et al. 2007) and lower self-perceived health (Krasnik \& Nielsen 2010). On top of that, studies indicate that ethnic minorities more frequently contact GPs and hospitals (Folman et al. 2006). Studies furthermore point to the fact that interactions with ethnic minorities are sometimes marred by barriers related to language and lack of a common understanding and recognition of health and disease patterns (Wittrup 2008; Nielsen 2005; Mygind et al. 2006). In summary, the literature pointed to significant health inequalities for the group in question. Against this background, Bhopal (2012) called for urgent action on a European scale. Here the patient involving pilot project 'Intercultural Health Promotion and Rehabilitation' was initiated.

\section{The intercultural health conversation}

At the core of the pilot project, 'The Intercultural Health Conversation' was introduced. Departing in a 5-question interview guide, the intercultural health conversation was intended to give access to complex illness experiences among ethnic minorities. The approach focused on aspirations for the future as a vital source for an intervention, in which the unique experiences of the individual patient were central. By focusing on aspirations for a better future health, the aim was to explore how the individual patient could possibly situate this in his or her social life. Allowing the patient's perception of 'a better future health' to unfold without constraining it beforehand neither to traditional notions of health and disease nor to stereotypical categories of ethnicity (Seeberg 1996; Jöhnke 1995). A better health in the future was thus to be an open theme to be explored providing a point of departure for an intervention.

By conducting the initial patient conversation they were both to engage in defining the individual health problem, and after each conversation they were mutually responsible for agreeing upon actions turning the conversation into an intervention. All health professionals where employed in health departments in the respective municipalities, most of them being a nurse. To overcome language problems, translators were offered. 183 patients participated in the project, being recruited through various sources (GPs, job centres, residential areas, educational centres, etc.). The common denominator was that they all had self-perceived health problems. 


\section{Conversations from an analytical perspective - Experience as narrative}

When approaching the intercultural health conversation this article draws on an existing anthropological corpus of theoretical discussions framing clinical encounters and conversations as possible places for experiences to unfold.

The notion of experience and its production has become the subject of increased attention among contemporary anthropologists. This has especially been the case within the field of medical anthropology where the individually and socially construed experience of sickness is seen as being in opposition to the traditional biomedical approach (Kleinman 1981; Young 1982). These theoretical debates have resulted in a keen interest in studying experience as it unfolds in practice. This has sparked an ever growing interest in approaching experience through the lens of its possible expressions. Expressions understood as representations, performances, objectifications, and texts (Turner 1986). Here anthropologists studying experiences of sickness within healthcare have turned their attention to the world of narratives as expressions of experiences in order to analytically grasp a world of individuals suspended in ongoing 'dramas' of life and death (Kleinman 1989; Mattingly 1998, 2008; Good 1994; Jackson 2006; Ochs \& Capps 1996, 2001; Steffen 1997).

Theoretically departing in the world of literature studies (Ricoeur 1984; Carr 1986), anthropologists have argued that there is an essential interrelationship between the construction of a narrative and life as experienced. They have increasingly approached the field of illness experiences using a narrative framework to duly understand agents entangled in a social world of sickness (Good 1994; Mattingly 2010; Steffen 1997).

Framed in a setting of clinical encounters and conversations it has been argued that, when engaging in constructing narratives, experiences are expressed as well as negotiated through the very social performance of telling them in time and space together with an audience acknowledging that there is always a listener and a teller (Mattingly \& Garro 2000; Ochs and Capps 1996).

Central to these works has been an increasing focus on the very practice of constructing narratives as a social ordeal within the healthcare system. And thus on the interrelationship between the listener and the teller, both being of central importance for what is being told. This means that narratives as expressions of experience are just as much constructed by the person listening as by the person telling the story. 
This interrelationship between teller and listener becomes of central importance when engaging in patient involvement focusing on experiences unfolded in the space of conversations in the healthcare system. And thus our analytical attention turns to the world of practice.

\section{Method}

In the project we collected data over a period of three years. Data consisting of 5 interviews with health professionals, 8 interviews with patients, 3 focus group interviews with patients, field notes from meetings among professionals, field notes from participations in 25 conversations and from 183 patient journals. Yet our choice in case material reflects our interest in exploring the deeper challenges entailed when approaching healthcare interventions provided for a vulnerable group framed around the notion of patient involvement. Here explicitly tied to accessing experience through the practice of conversations.

The conversation data presented were collected by one member of the research team who participated in 25 intercultural health conversations between patients and health professionals, taking field notes during sessions. In our study of narrative practice, we departed in analyzing the dialogue from these 25 conversations. Our main focus was aimed at analyzing dialogues concerning aspirations for health in the future, as these future aspirations represent a cornerstone in the intervention conversation. We then chose 3 conversations out of the 25. These 3 cases presented in our analysis have been chosen, because they each touch upon different vital aspects in their particularity when trying socially to negotiate patient experiences into a mutual viable intervention.

Analytically we approach the intercultural health conversation borrowing from Mattingly (2010) the concept of 'narrative acts', as a practice in itself. In practice, by unfolding how these narratives become 'emplotted' as a narrative act during the intercultural health conversation, allowing some stories to be told while others remain untold. 


\section{Narratives in practice}

\section{Yasmina}

Yasmina is fifty years old and of Kurdish descent, being born in Iran. Her husband was employed in the local government, but a general uprising forced Yasmina and her family to flee. They fled through Iraq and Turkey before arriving in Denmark as refugees 17 years ago. Yasmina has 4 children, and is currently unemployed. Accompanying her in the conversation is a local interpreter. The health professional begins her line of questions focusing on future aspirations and health:

Hp1: We are going to look at the future; what do you wish for?

Y: That my children become educated, that I learn Danish and that I can have a good life.

Hp1: What do you mean by a good life?

Y:I wish my children can stay clear of trouble. I wish for freedom for my children.

Hp1: Do you want to go home to your home country at a later stage in your life?

Y: If it is peaceful - yes (with a determined voice).

Hp1: You mentioned that you wish for a good life for your children. What do you mean by that?

Y: They need to get a good education. I will help them.

Hp1: It's wonderful when the children are doing well. Will it make a difference for the way you go about in your life in Denmark if Iran doesn't become a free country in the future?

Mentioning the possibility that Yasmina's home country may in fact never become free immediately prompts Yasmina to answer:

Y: I need to go back to Iran and work for a free Kurdistan. I want my own flag!

Hp1: But do you think your children would want to follow you? 
Y: Definitely; and they will get to use their educations in their homeland.

Hp1: But maybe they have a life here; I mean they grew up here.

Y: They really want to go home to Iran. They may have grown up in Iraq, but they want to go home to Iran and help rebuild. But of course noone knows what can happen years from now.

The health professional pauses for a moment:

Hp1: You're a strong woman. We also need to talk about your health. Are you healthy or sick?

Yasmina looks at the health professional as caught by surprise by the question. She engages in a long conversation with her interpreter. Yasmina tells about several incidents when her refugee camp was bombed, and the health professional asks if she has received help. Yasmina answers that she has already been seeing a psychologist, but she feels that her stories are not being accepted by the therapist; she is also afraid of 'falling in' again. The health professional continues:

Hp1: Seeing a psychologist may be a good way of talking about your problems. It can make you whole again. [...] Have other people helped you?

Y: Most of my family live far away, but my brother occasionally helps out.

Hp1: How is your day-to-day life?

Y: I cook, clean, watch Turkish television and sometimes go shopping for clothes.

Hp1: Who are you with, when shopping for clothes?

Y: My sister, no friends.

The conversation continues, touching upon the employment status of Yasmina, before finally ending in the prioritizing recap leading to an intervention for Yasmina.

Hp1: Do you see any opportunities for having a good life in Denmark?

Y: $50 \%$ chance. Here you have to work really hard to take care of yourself. 
Hp1: You have to contribute and take care of yourself yes. I can tell that you are doing well, but the problems you are having are due to the thoughts in your head.

Y: I hope I can get rid of them.

She answers with a distant look in her face.

Hp1: There is a possibility of getting psychological therapy at the centre for traumatized refugees. Maybe you could talk to your doctor about getting a referral. I don't think a group intervention is what you need.

Y: But I would still really like a group intervention.

The health professional suggests an individual intervention and Yasmina agrees in the end to the suggestion for psychological therapy. On top of that she is subsequently offered company by the health professional in upcoming doctor appointments with Yasmina.

\section{Malik}

Malik is at the end of his fifties and coming from Syria but has lived in Denmark for the last 20 years. He has worked in pharmaceuticals for the United Nations, but since his arrival in Denmark he has mainly been occupied as a shopkeeper. Malik has type 2 diabetes and he has been referred to the health conversation by the diabetic outpatient clinic at the hospital. The conversation is scheduled to take place at a local rehabilitation centre close to Malik's home. He arrives joined by his daughter who intends to act as a translator, but also clearly states to act as an 'extra set of ears' to make sure that he is offered proper treatment.

The health professional smiles at Malik

Hp2: You have been referred because of your diabetes? Have you ever attended a course before?

Malik seems distracted and doesn't answer.

Hp2: How long have you been a diabetic?

Ml: 5-6 years.

Malik becomes distracted and starts waving at a man passing the window outside. 
Hp2: Many people know you?

D:My father was a greengrocer.

Ml: I used to have my own store, but it went bankrupt. (looking sad)

Now I work in my son's store.

Hp2: How many children do you have?

Ml: 6, all good.

Hp2: How do you feel about not having a store anymore?

Malik clenches his fingers as he responds: I help my son.

Hp2: And that works ok?

Malik doesn't answer.

The health professional looks down at her papers:

Hp2: You say that you have diabetes. What do you dream of when you look three years into the future? You say that you ....

The health professional is interrupted by Malik.

Ml: My life is over

Hp2: How?

Ml: I can't work anymore. I used to be able to think. Now I am sick. I can't think anymore. I can't travel. I become dizzy.

Hp2: How would you like things to be in 3 years?

Ml: I never thought about it here in Denmark.

Hp2: Try to describe what you do when you wake up.

Malik explains how he works 3 hours in the shop. He used to be able to talk all day, but now he becomes increasingly physically and mentally affected to a degree affecting his patience when interacting with shoppers. 
Ml: This is not good for a tradesman.

The health professional responds to Malik's story from the shop.

Hp2: I hear that you have been active and that you are becoming increasingly impatient. But what about your disease?

Ml: I have problems with cholesterol and my heart. Now I can't work anymore.

Hp2: Is being healthy the same as having a job?

Ml: Yes working is good.

Hp2: What are you afraid of?

Ml: That I will lose my legs. I need to work; I need to earn money.

Malik talks about his daily activities with friends and family. Especially his grandchildren. As he talks, he is constantly smiling, yet, this changes when the health professional suddenly introduces the prospect of retirement.

Hp2: How do you feel about having to retire soon?

Ml: Retirement is no good. It's the same as being a living dead.

Malik's daughter again participates in the discussion.

D: Even if his disease becomes better, he still won't be allowed to work.

Ml: I know many pensioners; they go to their apartments and sleep all the time. That's no good. What am I to do?

Hp2: You talk a lot about family and friends, but what are you going to do with retirement life? What is a good life as a pensioner?

Malik looks somewhat puzzled at his daughter and they briefly converse in Arabic.

Ml:I don't know

Hp2:You don't need to name a particular activity. 
Malik talks to his daughter again:

D: He doesn't know.

Hp2: What about your parents, Malik? How was their life when they were old?

Ml: I don't understand.

Hp2: What was good in their life?

Ml: I don't know.

The health professional looks at the notes she has been jotting down during the conversation. She briefly sums up what she feels could be a suitable intervention for Malik.

Hp2: You are from Syria. You have worked really hard and you are in doubt about what is going to happen to you. You care a lot about your family.

Malik's daughter now joins in:

D: He is a really sensitive person who cares about his family.

Hp2: Diabetes occupies a big spot in your life. I think we should meet again. I think you need to know more about diabetes. What do you think?

Malik looks down, replying:

Ml: ok

The health professional continues to explain how receiving dietetic counselling is an option along with a general exercise programme. Malik's daughter once again joins the discussion in a raised voice:

D: I really want to say that if he just lost some weight. I mean he really knows a lot (about diabetes). I would really like for him to do some exercise.

Hp2: But is that what he wants?

A further meeting is scheduled and the health professional informs Malik that she will check the possibilities for a course focusing on diet and exercise.

Malik gets ready to leave and looks at the health professional uttering: 
I don't love money; I love to work.

Mai

M: "Probably, I don't have a lot of future left."

The conversation with Mai takes place in her sparsely furnished and cold flat in a deprived area. She was born in Thailand in an ethnic Chinese family; she speaks Thai, understands Chinese, but does not speak the language; she feels Chinese and wants to socialize with Chinese in Denmark apparently not being a mutual desire. In Denmark she meets her Danish husband, from whom she is now divorced; she appears both lonely, marginalized and quite unhappy, cries a lot and opens the conversation by stating that she doesn't think she has a future.

Hp3: Are you old?

M: No, perhaps not but you have a job and live a normal life!

Hp3: Where do you want to stay?

M: Doesn't matter as long as I'm happy, I too dream about a family. I dare not dream. Perhaps like you - not being alone ...

Hp3: What is a good health?

M: ?

Hp3: If I feel good, how then?

M: Just like you!

Hp3: But how do you think that I live?

M: You can get up in the morning, see the sun, live normally, but I can't ... work!

Hp3: What do you want to do?

M: I've tried everything and I'm good! I have been independent designing clothes, buying clothes in China and Hong Kong, but now I'm empty ... I'm dead alive! 
The health professional now follows the theme of 'normalcy' and engages in questions about everyday life:

M: I can't concentrate, forget to put on both my socks. Forget the frying pan. My jaw and my eyes are problems too. I'm fighting to get help.

Hp3: Do you get up early?

M: No, I sleep. I can't find anything hard to sleep on. I've spent a lot of money but everything is expensive. I walk into doors (shows her glasses). As if I don't want to see the door!

Hp3: Do you cook for yourself?

M: But I have problems shopping. I go for milk, but don't buy it. Even when I write it down!

Now the health professional returns to the food, triggering a line of symptoms in Mai:

M: I don't eat breakfast, but lunch. My intestinal system is malfunctioning, I burp a lot, have had ulcer, haemorrhoids, my muscles are totally stiff. I can't live like others. If I had family (crying) .. I can't, my muscles are tense.

Hp3: But you came to the meeting, so you do come out?

M: Yes and no, they will pick me up if I don't come. I'm also struggling to maintain my car. If I take the bus I forget and get pain. I have to leave in due time because I can't remember anything. I have to use GPS. That's my life, I'm dead alive!

Again shifting the subject, the health professional now turns to the outer world: Hp3: But you have a contact person?

M: But she doesn't listen; she only talks. Not like you. You care for me, you get to know me before trying to help me (smiles happily). But if she cannot help me then I don't have to worry about her. She says "one thing at a time". She is young, but very firm; she wants me to listen to her. She doesn't listen herself. I can't stand when people speak firmly to me. She is young but very firm. I've called the shelter myself, but she gets angry. Now she does neither answer her phone nor SMSes. Now she is 
angry. She wanted to help me applying for early retirement, but that is now a year ago ... I have the toughest of lives ...

Hp3: Maybe together we could try to sort it out?

M: I have so many helpers and I have to start all over each time, if I don't take my medicine.

The strong drive now leads the health professional to a surprising, though a bit hesitating invitation from Mai:

Hp3: Can I call the social worker?

M: Er... Yes for you know better, you listen; you don't talk; you know me better than she does. She doesn't help because I'm not allowed to do anything when she takes control.

Hp3: What I want to do is to come back and talk to you again.

M: I would like that and I want to talk about the body.

They agree to meet again.

\section{Emplotting tales of possible futures of health}

When approached collectively, the three conversations presented above all show aspects of the intricate process of engaging in constructing a social narrative that can lead to a subsequent intervention. For Yasmina and Malik their conversations show certain analytical similarities pertaining to the course of the conversation and the process of emplotting the story with aims of achieving certain plot ends to their story.

Naturally both conversations share the structure framing a story of future aspirations as specified in the conversation interview guide. As both conversations progress it nevertheless becomes apparent that both Yasmina and Malik and the health professionals respectively become entangled in constructing a story that inherently contains competing plotlines.

Yasmina's story opens with her definition of "freedom for her country as a social endeavour" as means of emplotting her aspirational story. While her story is 
initially accepted by the health professional, Malik's story on the other hand is immediately framed by the health professional tying aspirations for the future with his apparent somatic condition.

Nevertheless Malik is persistent when insisting on emplotting his story of aspirations for a better future out of the somatic frame and into a story of 'work and social relations'. But even though Yasmina and Malik insist on keeping their plot central to the story as a potential trajectory towards a possible future throughout their conversation, both plotlines become challenged by the health professionals. Yasmina's plot of a 'free home country' and Malik's plot of 'work and social relations' are both countered by the health professionals using a similar strategy of emplotment. Imposing a 'what if' plot to their stories respectively. In Yasmina's conversation the 'what if' plot being 'What if Iran never becomes a free country?' in Malik's conversation being 'What would a future be like, if work is out of the question - life as a retiree'? Thereby the professionals emplot the story by making both Malik's and Yasmina's plots into abstract ideas. Malik and Yasmina, however, object and instead they cling to their own plotlines.

In both Yasmina's and Malik's conversation, their obstinate approach to this new emplotment of their story prompts the health professional to pursue other trajectories/plots of potentiality. For Yasmina the health professional emplots the story towards one of individuality, linking it with health and sickness, thereby trying to steer the story plot towards one of 'becoming whole again', something to be achieved as a result of therapeutic aid. In Malik's conversation, the health professional returns to a somatic plot of diabetes, offering dietetic counselling and exercise clearly influenced by Malik's daughter's participation in the conversation.

Emerging out of both conversations is a picture, that although the health professionals in question both participate in exploring Yasmina's and Malik's unfolding plotline, they nevertheless emplot their respective stories following different trajectories.

In Mai's case, already the opening dialogue, the first four verbal exchanges place them apart. When the health professional asks What is a good health it symptomatically triggers a non-verbalised question mark, compelling the health professional to reformulate health into feel good and furthermore emplotting it using her own personal life as an engine. This plot makes sense to Mai, she gets the opportunity to introduce a plot of 'normalcy', here framed around work. The health professional does pick up work, but Mai's experience of work - apparently being an independent, successful businesswoman in Asia - is not followed as a possible 
trajectory by the health professional. Instead she introduces another dimension of normalcy, namely everyday life in its most universal form: when to get up, and how to cook.. She describes difficulties when shopping or simply finding her way round. Mai takes this opportunity to indulge in expressing all kinds of psychological, physical, and bodily malfunctions, again underlining her most inner aspiration of achieving a normal life. The sheer incoherence of Mai's storyline of normalcy compels the health professional to respond by introducing a positive theme of 'Leaving the home and breaking the social isolation'. Thereby emplotting the story of Mai's life in a frame that touches upon challenges from 'the system'; the health professional being innocently ignorant of the terrible encounters Mai has already suffered here.

In Mai's conversation, incoherence prevails disturbing the health professional's many attempts of emplotting 'a future healthy life'. They are all challenged by Mai who insists on unfolding a plot of normalcy in connection to work, everyday life and family life as well as in connection to her somatic and mental health. The health professional responds to Mai's continuous emplotment, but not as emplotment towards a story of normalcy, instead as an incoherent and fragmented set of plotlines presumably being her inner aspiration. The health professional still struggles with a fragmented story and chooses to offer Mai another meeting, hoping to get a new chance of constructing a coherent plot that can lead to an intervention. This, however, never happens. Reflecting over the case in a later interview the health professional states that she was afraid that Mai's case had the potentiality of swallowing her completely, which is why she chose to withdraw from it, leaving Mai with whatever support she can get. Concluding, she states that ... no one can solve her problems. So we have to say that it is not everybody we can help. Until they feel helped (Interview, health professional)

Looking at our cases reflected in our opening perspective on patient involvement, it quickly becomes apparent that engaging in the practice of expressing experience as a means of constructing patient involvement can definitely not be considered an easy affair. The three cases all reveal willingness on behalf of both health professionals and patients in mutually exploring patient experiences as potentially open ended stories framing a possible future. Yet as these stories progress, certain tendencies spring to mind, revealing that this open ended explorative narrative universe becomes challenged. Challenged by the fact that health professionals, although eager to respond to the open-ended stories, still have to 
place the patient's narrative within a frame that makes sense to them (Macintyre 1981), and thus a frame where plot and coherence makes sense to them.

Yasmina's and Malik's stories both start with an open exploration of their aspirations; yet gradually these stories become increasingly narrow, emplotted by the health professionals as the conversations draw towards the end and thus need to be transformed into possible interventions. In both cases, open-ended stories are transformed into stories with an end.

Equally Mai's story takes its beginning in an open exploration. Yet here the health professional finds herself entangled in what seems to be a completely fragmented story lacking a clear coherence, making narrowing of the story impossible. In an attempt to construct an end to the narrative within the conversation the health professional jumps from plot to plot, but due to a lack of coherence, doesn't realize that they all individually contribute to Mai's plot of 'normalcy'; she therefore chooses another meeting as a solution, before eventually giving up.

\section{Discussion \& perspectives}

This article opened exploring recent tendencies towards patient involvement framed around the idea of integrating patient experiences as a central part of providing health care services. Although acknowledging the prime importance of 'experience' to the relevance and success of healthcare, we found that little attention was given addressing the notion of experience in itself. Experience was generally approached as something implicit, belonging to the patient to be directly understood by the health professionals and integrated in the health intervention through the act of talking in conversations in healthcare. Yet in this article we approached the notion of experience in patient involvement from an anthropological perspective seeing experiences as constructed through social negotiations between patients and health professionals.

Drawing on a narrative approach to negotiated experience we analyzed three intercultural health conversations from the patient involving pilot project "Intercultural Health Promotion and Rehabilitation" between ethnic minority patients and health professionals.

These examples of patient involvement show that when experience is constructed during conversations through mutual storytelling practices; 'there are stories and there are stories'. This reveals a central challenge to the paradigm of patient involvement integrating patient experiences, a challenge which exactly 
pertains to their negotiated nature. As our analysis shows, when experiences become socially negotiated through storytelling, questions necessarily arise. Questions concerning the possible boundaries for what stories can actually be told. What experiences can become the platform for patient involvement?

As we have demonstrated in our empirical conversations, when experiences become expressed through a socially negotiated emplotment process, the stakeholders of the conversation become mutually interdependent in framing the possible trajectories for patient involving care interventions. Our material reveals that when stakeholders become placed in mutual interdependency in practice boundaries and constraints emerge. Looking closer into our case material while narratives framed around plots concerning nutrition, physical exercise and practical everyday doings are addressed, grand narratives containing plots relating to belonging, independence and parenthood where health and disease for patients are intertwined are left un-addressed. Where does that leave patient experiences in patient involvement?

Without proper attention towards understanding the delicate situation of negotiating experience as a social act in conversations leading to patient involvement, one could fear that the results could be patient involvement based on certain 'versions of experience'. Here understood as versions defined within constrained boundaries during conversations. Here patient involvement aimed at ethnic minorities presents an extra challenging dimension, as negotiating experience based on conversations is furthermore marked by barriers pertaining to language, cultural, and social categories.

Echoing fellow anthropologists one could fear that when patient involvement becomes tied to negotiated experience practiced through mutual storytelling, a lack of awareness of the fragility of mutual dependency could lead to 'a politics of storytelling' as argued by Jackson (2006) and Steffen (2005) potentially leaving patient involvement with certain versions of experience while excluding others.

Rather than pass judgment on the basis of our empirical material, we wish to encourage a further discussion promoting increased attention towards exploring the boundaries in practicing patient involvement based on the notion of experience. 


\section{References}

Aujóulet, I., d'Hoore, W., Decacche, A. (2003) Patient empowering in theory and practice: polysemy or cacophony? Patient Educ.couns. , 66, pp: 13-20

Bhopal, R. (2012) Research agenda for tackling inequalities related to migration and ethnicity in Europe.Journal of Public Health, Vol. 34, No. 2, 02.2012, p. 167-173.

Carr, D. (1986) "Narrative and the Real World: An Argument for Continuity", History and Theory, Vol. 25, No. 2, pp.117-131.

Coulter, A. (2011) Engaging patients in healthcare. England \& New York: Open University Press.

Coulter, A. (2012) Leadership for Patient Engagement. The King's Fund

European Commission (2012) Eurobarometer Qualitative study. Patient Involvement. Aggregate Report, May 2012. Conducted by TNS Qual+ at the request of the European Commission, Directorate-General for health and Consumers

Folmann, N.B. \& T. Jørgensen (2006) Etniske minoriteter - sygdom og brug af sundhedsvæsenet - et registerstudie. København:Sundhedsstyrelsen.

Good, B. (1994) Medicine, rationality and experience : an anthropological perspective. Cambridge University Press.

Institute of Medicine. Committee on Quality of Health Care in America (2001) Crossing the Quality Chasm. A New Healty System for the 21st Century. Washingson: National Academies Press.

Jackson, M. (2006) The Politics of Storytelling. Violence,Transgression and Intersubjectivity Museum, Tusculanum Press.

Jöhnke, S. (1995) "Hvis Kultur?", København: Hiv-Danmark

Kleinman, A. (1981) Patients and healers in the context of culture: An exploration of the borderland between anthropology, medicine and psychiatry. Berkeley: University of California Press.

Kleinman, A. (1989) The Illness Narratives: Suffering, Healing, And The Human Condition. Basic Books

Kristensen, J.K., Bak, J.F., Wittrup, I., Lauritzen, T. (2007) Diabetes prevalence and quality of diabetes care among Lebanese or Turkish immigrants compared to a native Danish population. Primary Care Diabetes, 1(3), pp. 159-65

Lomborg, K. (2013) Tiltrædelsesforelæsning: Hvad er patientinvolvering, og hvordan virker det? in Klinisk Sygepleje 27. Årgang, nr. 4

Macintyre, A. (1981) After Virtue: A study in Moral Theory. University of Notre Dame Press.

Mattingly, C. (1998) Healing dramas and clinical plots: the narrative structure of experience. Cambridge University Press.

Mattingly, C. (2005) "Den narrative udvikling i nyere medicinsk antropologi." Tidsskrift for forskning i sygdom og samfund, Nr. 2, pp. 13-40.

Mattingly, C. (2008) "Reading Minds and Telling Tales in a Cultural Borderland." Ethos, vol. 36, issue 1 pp. 136-154.

Mattingly, C. (2010) The Paradox of Hope. Journeys through a Clinical Borderland. Los Angeles: University of California Press

Mattingly, C., \& Garro, L.C. (2000) Narrative and the cultural construction of illness and healing. Berkeley, Calif.: University of California Press. 
Mockford, C., Staniszewska, S., Grifiiths, F., Herron-Marx S. (2012) The impact of patient and public involvement on UK NHS health care: a systematic review. Int J Qual Health Care 24:28-38

Mygind, A., Kristiansen, M., Krasnik, A., Nørredam, M. (2006) Etniske minoriteters opfattelse af sygdomsrisici - betydningen af etnicitet og migration. Sundhedstyrelsen

Nielsen, S., Krasnik, A. (2010) Poorer self-perceived health among migrants and ethnic minorities versus the majority population in Europe: a systematic review. International journal of public health. Oct;55(5):pp. 357-71

Nielsen, A. S. (2005) Smertelige erfaringer - en antropologisk analyse af migrantkvinders fortællinger om sygdom, marginalisering og diskursivt hegemoni. København:Institut for Folkesundhedsvidenskab.

Ochs, E. \& Capps, L. (1996) Narrating the Self. Annual Review of Anthropology, 25, pp. pp. 19-43.

Ochs, E. \& Capps, L. (2001) Living narrative : creating lives in everyday storytelling. Cambridge, Mass.: Harvard University Press.

Ricoeur, P.(1984) Time and Narrative Vol.1: The University

of Chicago Press

Riskjær, E. (2012) Patienten som partner: Handlemuligheder og effecter. Notat. Aarhus: CFK, Folkesundhed og Kvalitetsudvikling, Region Midtjylland

Riskjær, E. (2014) Patienten som Partner. En nødvendig Idé med Ringe Plads. Syddansk Universitets forlag, In Press

Seeberg, J. (1996) "Det er nok noget kulturelt" Sygeplejersken ed.33 30-33

Sheridan, S.L. (2004) Shared decision making about screening and chemoprevention: A suggested approach from the U.S. preventive service task force. In: American Journal of Preventive Medicine, 26(1): 56-66.

Singhammer, J. (2008) Etniske minoriteters sundhed. Center for Folkesundhed:Region Midtjylland

Steffen, V. (1997) Life Stories and Shared Experience. Social Science \& Medicine, Vol. 45, Nr. 1, s. 99-111.

Steffen, V. (2005) Erfaringspolitik - Om Brug af Fortællinger I Medicinsk Antropologi. I Tidsskrift for Forskning i Sygdom og Samfund. Nr.2

Thomson, A.G.H. (2007) The meaning of patient involvement and participation in health care consultations: A taxonomy. 64:1297-1310.

Turner, V. (1986) Dewey, Dilthey and Drama: An essay in the anthropology of Experience. In Turner, V., Bruner, E., (1986) The Anthropology of experience, University of Illinois Press.

Wittrup, I. (2008) InterMultiFemina - en antropologisk analyse af etniske minoritetskvinders narrativer om sundhed og trivsel. Århus: Region Midtjylland.

Young, A. (1982)The Anthropologies of Illness and Sickness. Annual Review of Anthropology Vol. 11, pp. 257-285

Zimmermann, C., Del Piccolo, L., Finset, A. (2007) Cues and Concerns by patients in medical consulations: A literature review. Psychological Bulletin Vol.133, No.3 pp.438-463 